\title{
COMICIOS 2014 Y LA VICTORIA DE NARENDRA MODI: ¿DESARROLLO ECÓNOMICO O POLARIZACIÓN SOCIAL EN INDIA?
}

Beatriz Martínez SaAvedra

El PRESENTE ARTíCUlo EXAMINA el proceso electoral de 2014 para primer ministro en India con un enfoque particular en la candidatura y trayectoria de Narendra Modi. Como jefe de gobierno del estado de Gujarat, Modi invirtió un gran esfuerzo y capital para construir gradualmente una imagen progresista que le rindió ventajosos dividendos políticos sobre sus adversarios electorales. De la mano de su plataforma política, el Bharatiya Janata Party (BJP), el político terminó con la etapa del virtual monopolio gubernamental del Congreso que había sido blanco de inconformidad social creciente en los últimos años. En este sentido, supo canalizar la inconformidad de sectores de la población hacia una administración plagada de corrupción y también logró persuadir a quienes no compartían sus fundamentos ideológicos de nacionalismo hindú. Primero analizaremos de manera general el surgimiento y posicionamiento en la esfera pública del BJP para luego enfocarnos en Narendra Modi, su trayectoria política y las expectativas de su triunfo para la sociedad india con el objetivo de realizar una prospectiva de los posibles cambios que se avecinan con su particular tendencia política.

Con la promesa de emular el crecimiento exitoso del estado de Gujarat a un nivel nacional, Narendra Modi (exjefe de gobierno de ese estado durante trece años) se erigió como el primer ministro de India en las pasadas elecciones de abril-mayo de 2014. Su sonora victoria sobre la United Progressive Alliance (UPA), que incluye al partido del Congreso entre otros, acaparó una mayoría 
abrumadora en la Lok Sabha (cámara baja de la asamblea) para su partido con 284 escaños. A pesar de que el porcentaje de voto general fue de un $31 \%,{ }^{1}$ el triunfo del BJP articulado de esta forma le permite constituir una mayoría simple sin verse obligado a establecer alianzas.

Desde la independencia, el partido del Congreso había ejercido el gobierno central de manera casi monopólica salvo por algunos interludios. El primer desplazamiento del Congreso de la administración nacional ocurrió en 1977, cuando una coalición de partidos, conocida como Janata Party, se unió para hacer frente al Congreso, al cual derrotó luego de la imposición de la emergencia por Indira Gandhi. De esta coalición, el Jana Sangh se convirtió en 1980 en el вJP, que ha sido un partido de tendencia nacionalista hindú o de Hindutva, es decir, con una idea de subordinación de las manifestaciones culturales de minorías no hindúes. A pesar de que en su ideario político fundacional el BJP refería enarbolar la bandera de un socialismo gandhiano ${ }^{2}$-tendencia que para el partido combinaba la búsqueda de la humanidad por satisfacer bienes materiales y espirituales ${ }^{3}-$, tanto éste como su antecesor político, el Jana Sangh, recibieron una influencia crucial del Rashtriya Swayamsevak Sangh (RSs) ${ }^{4}$, organización que promueve un hinduismo militante, en particular en cuanto al principio supremacista de que los no-hindúes en India debían adoptar una cultura hindú y aprender a respetar al hinduismo, es decir, dejar de ser "extranjeros" o, si no, permanecer en el país en un estatus subordinado sin poseer derechos de ciudadanos. ${ }^{5}$

\footnotetext{
${ }^{1}$ Ram Puniyani, "Modi Coming to Power: An Appraisal", Academia.edu [http: // www.academia.edu/8781597/Modi_coming_to_Power_An_Appraisal].

${ }^{2}$ Partha Ghosh, BJP and the Evolution of Hindu Nationalism: From Periphery to Centre, Nueva Delhi, Manohar Publishers, 1999, p. 87.

${ }^{3}$ Yogendra K. Malik y V. B. Singh, Hindu Nationalists in India. The Rise of the Bharatiya Janata Party, Nueva Delhi, Vistaar Publications, 1994, p. 61.

${ }^{4}$ Esta organización pertenece a la Sangh Parivar o familia de organizaciones hindúes junto con el Vishva Hindu Parishad (vHP) y el BJP que consideran a la cultura hindú como el fundamento de la identidad nacional. Véase Christophe Jaffrelot (ed.), Hindu Nationalism: A Reader, Princeton, Princeton University Press, 2007.

${ }^{5}$ Este ideario fue expresado por uno de los dirigentes del Rss, Gowalkar.
} 
Desde sus años iniciales y siguiendo la línea política del Jana Sangh, el вJP se fundó para hacer contrapeso al Congreso, al que criticaba de corrupción. Posteriormente, el BJP también enfatizaba en el Congreso una actitud que definía como "entreguismo a las minorías", en referencia a los musulmanes en particular. Con ello el partido condenaba una supuesta actitud de sometimiento ante las demandas de los sectores minoritarios que bajo esta óptica se veían beneficiados en detrimento de la mayoría hindú. Esta idea no era nueva. Desde los años previos a la partición de India y al surgimiento del Pakistán, se había cuestionado la postura que el gobierno adoptaba hacia los musulmanes, una de supuesta sumisión que habría traído como consecuencia la partición de la nación india como culminación de las demandas de sectores musulmanes para la creación de su propio país. El BJP, siguiendo esta línea de pensamiento, cuestionaba esas canonjías para los musulmanes y abanderaba la causa hindú. Este punto encarna una de las contradicciones más grandes al gandhismo que el вJP refería profesar, pues algunos factores concomitantes en el ideario político de Gandhi eran la idea de unidad entre hindúes y musulmanes y el derecho a la expresión de sus propias manifestaciones culturales. ${ }^{6}$ Por el contrario, el BJP se ha opuesto a esta premisa buscando el sometimiento de la cultura de las minorías a los marcadores hindúes de identidad.

El posicionamiento en la esfera pública del BJP se consolidó en la década de 1990 con un fenómeno de diversificación política que permitió la reconfiguración de fuerzas y actores. En este proceso se articularon políticas regionales más distintivas en cada estado con culturas políticas específicas y emergieron partidos regionales con los que los partidos principales tuvieron que establecer alianzas para poder llegar a la población de esas regiones. ${ }^{7}$ En particular, el BJP articuló en diferentes estados alianzas de diversos tipos con partidos locales. En Maharashtra, por ejemplo, vecino de Gujarat,

Véase Geeta Puri, Bharatiya Jana Sangh: Organisation and Ideology, Delhi: A Case Study, Nueva Delhi, Sterling Publishers Pvt. Ltd., 1980, p. 13.

${ }^{6}$ Malik y Singh, op. cit., p. 62.

${ }^{7}$ Christophe Jaffrelot y Thomas Blom Hansen (eds.), The BKP and the Compulsions of Politics in India, Delhi-Nueva York, Oxford University Press, 1998. 
se alió con el Shiv Sena que también es un partido consecuente con una ideología fundamentalista hindú. Sin embargo, en Uttar Pradesh el вJP se alió con el Bahujan Samaj Party, un partido de adivasis o grupos tribales. ${ }^{8}$ Así, si en los años ochenta el BJP apelaba a la clase media urbana, en los noventa su agenda social podía ser transfigurada de acuerdo a las circunstancias para cooptar otros grupos en desventaja económica. En contraste con la noción de hinduismo del вJP, que es una expresión brahmánica o de castas altas, dicha coalición resultó demasiado forzada en términos de coincidencia de agenda social y política. ${ }^{9}$ No obstante, esta diversidad de alianzas demuestra la flexibilidad política del BJP en el afán de ampliar su radio de acción entre sectores sociales que de otra forma quedarían excluidos de su influencia.

En este sentido, otro factor de importancia para la diversificación de su agenda fue la entrada a la esfera política de grupos conocidos como Other Backward Castes (овC) y Scheduled Castes (SC), que contribuyeron grandemente a la transformación de la escena pública de India. Se estructuró una política de discriminación positiva que se traducía en asientos reservados o espacios laborales y educativos para estos grupos. Este desarrollo político causó gran descontento entre sectores mejor posicionados en la escala social. La inconformidad de dichos sectores se hizo patente en la construcción de un discurso de "meritocracia" que rechazaba el acceso a los puestos y espacios educativos para los OBC y SC por su mera vulnerabilidad social. Como consecuencia a este panorama se sumó una mayor participación de castas altas y medias urbanas en una política nacionalista hindú que protestaba contra lo que era llamado la "plebeyanización" de la política. Esto hacía alusión a la discriminación positiva para grupos que se consideraban social y económicamente en desventaja. El вJP capitalizó este descontento y sus demandas se ampliaron; ya no eran sólo contra la corrupción

${ }^{8}$ Badri Narayan, Fascinating Hindutva; Saffron Politics and Dalit Mobilisation, Nueva Delhi, Sage, 2009.

${ }^{9}$ Sin embargo, el BJP supo apelar a los adivasis al buscar influir en sus mitos de creación cambiando sus historias en las que las castas altas figuraban como los enemigos de los adivasis. Con la intervención del BJP, se fomentó una imagen en la que los musulmanes devinieron en los opresores de los adivasis. Ibid., pp. 50-51. 
del Congreso, sino también contra las tendencias de "plebeyanización" política, aunque como se mencionó, el BJP ha estado dispuesto a modificar sus estrategias para incorporar a sectores en desventaja social como ha hecho con dalits (intocables) y adivasis. Además, su participación en este ambiente convulso intentaba, a decir del propio partido, introducir estándares más elevados de conducta para los representantes elegidos.

No obstante el esfuerzo de proyectarse desde su fundación como un partido ético y anti-corrupción, el BJP se ha conducido en diversos momentos con un proceder excluyente y divisivo. Sus líderes, como L. K. Advani, han sido notorios por articular campañas de polarización entre las comunidades. Advani, por ejemplo, orquestó en 1992 la destrucción de una mezquita del siglo XVI en Ayodhya, la Babri Masjid, al norte de India, bajo el argumento de la existencia de un templo hindú en el lugar de la mezquita y de ser el sitio de nacimiento del dios Ram. El propio primer ministro, Narendra Modi, tuvo un papel en esa campaña por la destrucción del recinto; destacó como un organizador del Rath Yatra o peregrinación que iba del templo de Somnath a Ayodhya. ${ }^{10}$ Esto marca un punto de referencia en el nacionalismo hindú ascendente que Modi ha desarrollado a lo largo de su trayectoria política. Las siguientes líneas analizarán la travesía que el político gujarati ha seguido para instalarse en el gobierno central. Repararemos en sus gestiones regionales, y en particular en su desempeño en los disturbios de Godhra en 2002 y en cómo logró trascender la desaprobación por parte de la opinión pública.

El hecho icónico de la administración de Modi como jefe de gobierno y que más le ha valido señalamientos han sido los disturbios de Gujarat en 2002, cuando más de un millar de personas perdieron la vida (algunas estadísticas hablan de más de 2000 personas), principalmente musulmanes. ${ }^{11}$ Modi asumió el cargo

${ }^{10} \mathrm{~J}$. Kuruvachira, Politcisation of Hindu Religion in Postmodern India. An Anatomy of the Worldviews, Identities and Strategies of Hindu Nationalists in Bharatiya Janata Party, Delhi, Rawat Publications, 2008, p. 251.

${ }^{11}$ Reporte de Amnistía Internacional 2005 [http://www.amnesty.org/en/library/asset/ASA20/001/2005/en/110d0c4c-d53a-11dd-8a23-d58a49c0d652/ asa200012005en.pdf]. 
de gobernador de Gujarat en 2001 y a unos cuantos meses de entrar en funciones tuvo que afrontar un episodio de violencia comunal de grandes proporciones. En febrero de 2002 el vagón de un tren detenido en la estación de Godhra se incendió. En él venían peregrinos hindúes provenientes de la ciudad de Ayodhya, misma que estuvo bajo los reflectores en diciembre de 1992 por la destrucción de la mezquita antes referida. Los kar sevaks o peregrinos habían ido a esa ciudad para conmemorar los diez años de la demolición del recinto islámico. Una versión del episodio es que un grupo de peregrinos había tenido un altercado con vendedores de té musulmanes quienes habían incendiado el tren. La controversia sobre el incendio continúa y hay versiones que incluso refieren que el siniestro se inició de manera accidental. ${ }^{12}$ Sin mayor claridad, luego de ese episodio se orquestó la venganza por la quema del tren contra la comunidad de los "incendiarios". Cientos de miembros de la sociedad civil perdieron la vida a manos de contingentes de agresores que se tomaron la "justicia" en sus propias manos. Modi pudo salir bien librado de las acusaciones de diversas organizaciones no gubernamentales y de testigos que lo inculparon por no actuar contra los grupos de atacantes y en algunos casos de la connivencia de su parte ante la violencia revanchista infligida hacia los musulmanes. Sus declaraciones se basaron en la formulación newtoniana de que "a cada acción corresponde una reacción” para referir que las masas actuaron espontáneamente por la quema del tren, lo que refleja una actitud de justificación de las hostilidades. Si esto no arroja pruebas sobre su omisión en actuar, sí muestra la nula sensibilidad del líder para reaccionar ante episodios de esta índole así como su clara parcialidad. Además, la funesta convocatoria a elecciones tempranas para la asamblea de Gujarat en diciembre de 2002, a unos cuantos meses del pogromo, reveló la determinación de Modi de sacar

12 Hasta ahora no hay certidumbre de la forma en que comenzó el fuego, pero la mayoría de las investigaciones coinciden en que se inició dentro del vagón y no desde fuera con piedras y objetos ardiendo. K. S. Subramanium, "Truth behind the Fire in Sabarmati Express", Mainstream Weekly, vol. 49, núm. 16, 9 de abril de 2011 [http://www.mainstreamweekly.net/article2684.html]. 
provecho electoral de la tragedia, el cual se hizo patente con el triunfo del вJP. ${ }^{13}$

Gujarat 2002 a la fecha no se ha esclarecido y todavía existe controversia sobre los acontecimientos. Entre los detractores de Modi se le sigue inculpando por ese hecho. Si bien la corte y el equipo especial de investigación (sIT por sus siglas en inglés) no encontraron evidencia para inculparlo, la poca atención a los desplazados de los disturbios, y lo que un estudio de la escuela de leyes de Stanford ha criticado como ineficiencia del Estado en declarar convictos en esos casos, ${ }^{14}$ tampoco aportan certeza para considerar al exgobernador de Gujarat totalmente inocente. En contraste, sus partidarios están de acuerdo con Modi mismo con que las críticas provienen de sectores políticos y sociales que quieren denostar la imagen de Gujarat. De este modo, su respuesta ante las preguntas sobre 2002 se reduce a referir metonímicamente que cuestionarlo por su proceder es poner en tela de juicio a los gujaratis en general, al compararlos con "saqueadores", "violadores" y "asesinos de musulmanes"; ${ }^{15}$ es decir, al envilecer la imagen de Gujarat y sus habitantes. Pero su estrategia, a grandes rasgos, ha sido evadir los cuestionamientos sobre los disturbios de 2002 y en cambio ser prolífico refiriendo el éxito económico de Gujarat, tema que se abordará en el último segmento de este texto.

Asimismo, Modi ha sido un persistente promotor de una noción del siglo xix que se conoce como Gujarat asmita u "orgullo de Gujarat”, la cual apela a mostrar altivez por una identidad regional gujarati. Sin embargo, esta promoción por parte del mandatario no ha sido ingenua y su discurso ha mostrado la supremacía que atribuye a lo hindú sobre expresiones culturales disímbolas. Como Modi mismo se ha definido y enorgullecido, él es un nacionalista hindú que coincide, como tal, con una ideología de hindutva que observa en lo hindú la dimensión que debe dar forma a la identi-

13 Nagindas Sanghavi, Gujarat at Cross-Roads, Mumbai, Bharatiya Vidya Bhavan, 2010, p. 180.

14 "Modi: from tea boy to India's leader", Aljazeera English, 27 de mayo de 2014 [http://www.aljazeera.com/news/asia/2014/05/modi-from-tea-boy-indiapm-20145139742599119.html].

${ }^{15}$ Kuruvachira, op. cit., p. 255. 
dad regional y nacional. Su retórica en periodos electorales ha subrayado que los musulmanes no le apoyan porque tienen lealtades extraterritoriales en Pakistán u otras regiones del mundo, no en India. ${ }^{16}$ De igual forma, ha mostrado poca empatía para los desplazados por la violencia de 2002 quienes en muchos casos decidieron no volver a sus hogares por temor a represalias; en cambio, Modi se refiere despectivamente a los refugios de musulmanes como "fábricas de hacer bebes". ${ }^{17}$ Sus omisiones, así como sus declaraciones y sus propios actos de gobierno han contribuido en diversos momentos a la polarización de sectores comunitarios.

Sin embargo, a pesar de la polémica existente sobre los disturbios de 2002, que el BJP haya llegado al gobierno central en las pasadas elecciones de 2014 en condiciones tan favorables plantea la interrogante sobre qué buscan los sectores sociales en la nueva administración y cuáles son las prioridades en la agenda política que los votantes vislumbran. Ciertamente la elección de Modi evidenció el hartazgo de la gente hacia un grupo gobernante que no superó el estancamiento de la economía y que hizo despliegues de corrupción a niveles alarmantes. Entre 2005 y 2008, la economía india alcanzaba un 9\%. Hacia 2009 la cifra se había reducido a $6.7 \%$ aproximadamente. ${ }^{18}$ Para 2010-2011 las estadísticas habían remontado a $9.3 \%$ para caer a menos de $5 \%$ en $2014 .{ }^{19}$ Aunado a esto, la falta de creación de empleos, falta de seguridad para las mujeres, las airadas acusaciones de grupos afines al BJP sobre la omisión del Congreso en atender temas relevantes de seguridad nacional fueron factores que influyeron en el mandato de la gente

16 Dipankar Gupta, Justice before Reconciliation. Negotiating a 'New Normal' in Post-Riot Mumbai and Ahmedabad, Nueva Delhi, Routledge, 2011, p. 24.

${ }^{17}$ Kuruvachira, op. cit. p. 255; y William Darlymple, "Narendra Modi: Man of the Masses”, New Statesman, 12 de mayo de 2014 [http:/ /www.newstatesman.com/ politics/2014/05/narendra-modi-man-masses].

18 "Planning Commission", citado en Rohini Hensman, "The Gujarat Model of Development. What Would it Do to the Indian Economy?", Economic and Political Weekly, vol. 49, núm. 11, marzo de 2014 [http://www.epw.in/web-exclusives/ gujarat-model-development.html].

${ }^{19}$ Además de la alta inflación y la devaluación de la rupia, el índice de precios en alimentos se incrementó 157\%. William Darlymple, op. cit. 
en un sentido opuesto al del Congreso. Narendra Modi supo no sólo capitalizar el descontento social, sino que aportó una importante contribución para exaltar los ánimos aún más contra ese actor político.

No obstante, desacreditar al Congreso no generó por sí solo la preferencia por Modi, aunque dicho descrédito, como se ha referido, ha sido una labor constante en la trayectoria política del BJP desde su fundación. En esta tesitura, no es de extrañar que la candidatura de Narendra Modi se orientara a resaltar los aspectos de corrupción y de estancamiento ecónomico de la administración del Congreso. La ofensiva contra los puntos débiles de sus adversarios electorales fue una estrategia efectiva porque, de hecho, éstos no poseían demasiados atributos para frenar lo que se denominó como "ola Modi”. Rahul Gandhi, candidato del Congreso y miembro de la dinastía política más importante en India, tuvo que afrontar no sólo las acusaciones de corrupción hacia su partido y un desarrollo económico mediocre, sino también la falta de conexión con el electorado y una campaña endeble que nunca cobró fuerza. ${ }^{20}$ Por su parte, el otro candidato, Arvind Kejriwal del Aam Admi Party (Partido del Hombre Común), quien también ha enarbolado la causa de corrupción apuntando también al Congreso y más tardíamente al BJP, no había sido considerado seriamente en las elecciones a primer ministro dado su historial político, que incluye su renuncia a unos cuantos meses de haber sido elegido como gobernador de Delhi en 2013, aunque ha vuelto a asumir el cargo en febrero de $2015,{ }^{21}$ lo cual podría ser una buena señal que muestra que existe la intención de acotar la gestión central del BJP.

Un aspecto decisivo de la campaña electoral de Modi fue su enfoque en proyectar una imagen progresista que el exjefe de gobierno de Gujarat se dedicó a cultivar a lo largo de sus administraciones regionales. Dicha campaña giró en torno a enfatizar

${ }^{20}$ Jason Burke, "Narendra Modi's landslide victory shatters Congress grip to India”, The Guardian, 16 de mayo de 2014 [http:/ /www.theguardian.com/world/ 2014/may/16/narendra-modi-victory-congress-india-election].

${ }^{21}$ William Darlymple, op. cit. 
o exagerar la prosperidad alcanzada durante los años de su administración en Gujarat, en la que Modi se concibió como el ministro del desarrollo y el progreso.

En este sentido, mucho se ha referido que el modelo económico de Modi ha sido exitoso; con todo, según estudios que establecen una comparación regional, el Gujarat de Modi no es un caso de excepcionalidad. ${ }^{22}$ El PIB en el estado ha sido superior al promedio nacional en los últimos diez años, pero al compararlo con el PIB de estados como Maharashtra o Tamil Nadu su desempeño ha sido equivalente. Ante este escenario, la pregunta pertinente frente al esquema de desarrollo de Gujarat y sus resultados es: ¿cómo era la situación económica de Gujarat en una época preModi? En este contexto, las estadísticas indican que hay fluctuaciones en los índices de crecimiento del estado. Entre 1994 y 2001, es decir, siete años previos a la llegada de Modi, Gujarat registraba un crecimiento promedio de 10 y 13\%; en 1994-1995 se registraban niveles incluso superiores a $13 \% .{ }^{23}$ De esa forma, en la década de 1990 Gujarat despuntaba entre los tres estados con mayor crecimiento. Los gobiernos de este periodo no fueron encabezados exclusivamente por el BJP; algunos también por el Congreso.

En consecuencia, si bien la administración que dirigía Narendra Modi registró notables niveles de crecimiento en diferentes momentos, no puede hablarse de una antítesis comparada con los gobiernos previos a Modi. En todo caso, si existe un rasgo de excepcionalidad en el laureado modelo económico de Gujarat está en la promoción de dicho esquema por el propio Modi y sus agentes de medios de comunicación. Modi se dio a la tarea de difundir esta noción de sí mismo en diversos medios. Para su campaña de promoción, Modi contrató de 2009 a 2013 a la renombrada firma estadounidense de marketing y relaciones públicas APCO Worldwide, que entre otras cosas, promovía al estado de Gujarat como un

22 "The Myth of Gujarat's Exceptional GDP Growth Under Modi”, 7 de octubre 2013 [http://www.centreleftindia.wordpress.com/2013/10/07/the-myth-ofgujarats-exceptional-gdp-growth-under-modi/].

23 Dipankar Gupta, “Gujarat: What Miracle?”, The South Asian Idea Web Blog [https://thesouthasianidea.wordpress.com/2009/03/18/gujarat-what-miracle/]. 
destino para inversionistas. ${ }^{24}$ A pesar de que se le ha descrito como un político austero, Modi contrató a la promotora con un costo cercano a 25000 dólares mensuales para desarrollar la campaña de Vibrant Gujarat, ${ }^{25}$ cumbres empresariales que desde el 2003 se han llevado a cabo en el estado para atraer inversionistas.

Cabe resaltar que la formulación de Gujarat como destino ideal de inversiones no es por sí misma tan atractiva. Más allá de una mera imagen cultivada por APCO, ha sido mucho lo que Narendra Modi ha ofrecido y, de hecho, brindado a los industriales para persuadirlos de invertir en Gujarat. Entre otras cosas, subsidios muy importantes con interés mínimo y préstamos a muy largo plazo. ${ }^{26}$ La privatización de diversos sectores también ha sido un rasgo clave en las administraciones de Modi y un imán para los inversionistas. Esto ha implicado una delegación de las responsabilidades del gobierno en las manos de corporativos y empresarios. ${ }^{27}$ Por lo anterior, industriales como el prominente Anil Ambani han mostrado gran predilección por el político. ${ }^{28}$ Éstos, como sus más fervientes adeptos han sido recíprocos con las prerrogativas ofrecidas en Gujarat, un estado que ha acogido a magnates como Ratan Tata cuando las negociaciones han sido infructuosas en otros estados. ${ }^{29}$ En consecuencia, Modi fue vislumbrado como el redentor en un periodo en que la economía está inestable y las inversiones así como la demanda de consumo se han reducido. ${ }^{30}$

24 "Modi: From Tea Boy to India's Leader".

25 Binoy Prabhakar, "How an American Lobbying Company APCo Worldwide Markets Narendra Modi to the World”, The Economic Times, 9 de diciembre de 2012 [http://articles.economictimes.indiatimes.com/2012-12-09/news/35689601_1_ apco-worldwide-vibrant-gujarat-niira-radia].

${ }^{26}$ Rohini Hensman, op. cit.

27 Ibid.

${ }^{28}$ Sameer Hashmi“Narendra Modi: India's economic saviour?”, $B B C, 17$ de mayo de 2014 [http://www.bbc.com/news/business-27412507].

${ }^{29}$ Nalin Mehta, "Ashis Nandy vs. The State of Gujarat: Authoritarian Developmentalism, Democracy and the Politics of Narendra Modi”, en Nalin Mehta y Mona G. Mehta (eds.), Gujarat beyond Gandhi. Identity, Conflict and Society, Delhi, Routledge, 2010, p. 172.

${ }^{30}$ Sameer Hashmi, op. cit. 
Por otro lado, si bien el gobierno de Modi fue notable por su apoyo a industriales, tal apoyo para el resto de la población no fue simétrico. Su abrumadora atención a los empresarios soslayó el desarrollo de sectores sociales más vulnerables. Para 2012, 40\% de la población del estado aún vivía bajo la línea de pobreza y satisfactores básicos como el abastecimiento de agua en Gujarat son una asignatura pendiente cuando mujeres de contextos rurales deben recorrer varios kilómetros para obtener el vital líquido. ${ }^{31}$ Más aún, en continuidad con su actitud parcial durante su administración se ha observado que los progresos llegaron a enclaves urbanos hindúes, no así a los guetos de musulmanes que carecen de los servicios básicos. Un claro ejemplo es el de los habitantes de Juhapura, el gueto más grande de musulmanes en Gujarat, que nunca fue siquiera visitado por Modi. ${ }^{32}$ Esta área de Ahmedabad fue poblada por musulmanes desplazados de los disturbios y la infraestructura, los sistemas de transporte rápido, sin mencionar drenaje, instalaciones sanitarias, abastecimiento de energía eléctrica o agua potable son factores que aquí no figuran. ${ }^{33}$ Esta población, por el contrario, se ve forzada a vivir en condiciones infrahumanas en zonas insalubres adjuntas a tiraderos de basura como es el caso de Citizen Nagar, un vecindario construido para la rehabilitación de los desplazados por organizaciones no gubernamentales islámicas, ${ }^{34}$ no así por las instancias pertinentes de la administración de Modi. Además de su cercanía a los tiraderos, también tienen la problemática de fábricas circundantes, lo que provoca que el aire esté contaminado con gases tóxicos que hacen insatisfactoria la calidad de vida.

${ }^{31}$ Rajeev Gowda, "Is the Development in Narendra Modi's Gujarat All Virtual?”, DNA, 21 de abril de 2014 [http://www.dnaindia.com/analysis/standpoint-is -the-development-in-narendra-modi-s-gujarat-all-virtual-1980563].

32 Surabhi Vaya, "Gujarat: 'We Don't Want Modi or BJP'”, First Politics, 1 de mayo de 2014 [http://www.firstpost.com/politics/gujarat-we-dont-want-modi-orbjp-say-muslims-in-juhapura-1503671.html].

33 Mahesh Langa y Divyaraj Gadhavi, “Ahmedabad's Segregated Muslims”, Aljazeera English, 30 de abril de 2014 [http:/ / www.aljazeera.com/indepth/inpictures/2014/04/pictures-ahmedabad-segregated-m-201442316259141306.html].

${ }^{34} \mathrm{Ibid}$. 
Si tantos asuntos sociales quedaron irresueltos, es necesario volver a la pregunta sobre cuáles son las demandas y prioridades de los votantes del pasado proceso electoral. Además de los industriales, otro sector persuadido por la campaña de Modi fueron las clases medias. El discurso del político enfatizó nociones de modernización, crecimiento y globalización que fueron atractivas para la población urbana como posibilidad de satisfacer sus necesidades económicas y también culturales, pues existe una confluencia entre las nociones de desarrollo del вJP con la de la ideología de Hindutva, que afianza su ideario en un proyecto modernizador para la nación india equiparada con la comunidad hindú mayoritaria. ${ }^{35}$

Los indicadores son claros en señalar que la búsqueda por una prosperidad económica fue el factor crucial para favorecer con el voto a Modi. Pero la decisión de los votantes de dejar en el pasado la no resolución de Gujarat 2002 hace eco de la propia postura displicente de Modi. Asimismo, la agenda pendiente con las víctimas de la violencia parecería indicar que el aspecto de justicia social y derechos humanos se subordina a una cuestión aspiracional de sectores de la población que buscarían un mejor nivel de vida entre sus legítimas prioridades. En esta tesitura, el discurso desarrollista del BJP se ha hecho acompañar de la idea de equidad como consecuencia lógica e inmediata del desarrollo y de índices elevados de crecimiento. ${ }^{36}$ Constituido en la opción de gobierno para los corporativos, las clases medias, comerciantes y las bases del Rss, Modi simboliza para cada uno de estos sectores la cristalización de sus aspiraciones. Los industriales buscan mayores privilegios y apertura del gobierno como la mostrada en Gujarat; las clases medias, la garantía de una mejora económica y el freno a minorías religiosas, y el Rss, la posibilidad de erigir una Hindu rashtra o nación hindú. ${ }^{37}$

La acogida del exjefe de gobierno de Gujarat no tiene la misma lectura entre todos sus seguidores. En el espectro de persona-

35 Tommaso Bobbio, "From Ahmedabad to Karnavati", en Sharmina Mawani y Anjoom A. Mukadam (eds.), Globalisation, Diaspora and Belonging. Exploring Transnationalism and Gujarati Identity, Delhi, Rawat, 2014, p. 256.

${ }^{36}$ Ibid., p. 258.

${ }^{37}$ Ram Puniyani, op. cit. 
lidades en que se desdobla Narendra Modi o en cómo se lo percibe polifacéticamente también está la clave para comprender el alcance del político hacia segmentos de la población que no coinciden con su ideología supremacista hindú. Entre las apreciaciones distintas del político están Modi como el campeón de la administración eficiente, Modi como el político incorruptible, como el político confiable con la capacidad de atraer inversionistas o incluso como el contendiente más popular. En el otro lado del espectro, Modi se dibuja como el gobernante autoritario de corte fascista que desdeña los derechos humanos, como el político comunalista que fomenta la polarización social.

Sus más entusiastas partidarios, los industriales, brindan su respaldo al político y canalizan sus recursos con la expectativa de recibir más ventajas para continuar su prosperidad. Empresarios como Mukesh Ambani se refieren a él como "un líder con gran visión y claridad de objetivos". ${ }^{38}$ Pero otros de entre la gente de a pie, favorecieron con su preferencia y votos a "Moti", como le llama una señora de Bengala occidental -un estado de tendencia socialista y gobernado por la izquierda-, porque todo el mundo habla de él. ${ }^{39}$ Correligionarios del político gujarati acuñaron el término "ola Modi" para referir un fenómeno de apoyo arrasador desatado ante el potencial de "esperanza y buen gobierno" que supuestamente prefiguraba la administración de Modi. ${ }^{40}$

De igual forma, incluso en los círculos académicos, estudiosas feministas como Madhu Kishwar se vieron volcadas ante la ola Modi y emprendieron la tarea de reivindicar al político por su actuación en Gujarat 2002. Para Kishwar, las críticas hacia Modi por los disturbios de ese año fueron orquestadas por el Congreso en un intento por destruirlo políticamente ante su popularidad creciente. Para la académica, hay un proyecto por demonizar a "NaMo", quien, según su perspectiva, es un personaje que, de

${ }^{38}$ Nagindas Sanghavi, op. cit., p. 204.

39 Tusha Mittal, "From Marx to Modi in West Bengal?", Aljazeera English, 27 de mayo 2014 [http:/ / www.aljazeera.com/indepth/features/2014/05/from-marx-mo di-west-bengal-201452711380973919.html].

${ }^{40} \mathrm{Ibid}$. 
hecho, supo poner freno al uso político de los disturbios. ${ }^{41}$ Aventurándose todavía más lejos, Kishwar sostiene que el Congreso habría sido el instigador del pogromo, dado el canal de comunicación que Modi habría comenzado a construir con los musulmanes, adeptos habituales del Congreso. ${ }^{42}$

Su postura es relevante dado el nítido contraste que se aprecia con la posición de otras voces, incluidas las de un sinnúmero de organizaciones no gubernamentales de derechos humanos que han documentado bien las omisiones para contener la violencia en Gujarat. ${ }^{43}$ Amnistía Internacional concluyó que el gobierno de Gujarat e India son responsables bajo la ley de los derechos humanos internacionales de no tomar las diligencias apropiadas para prevenir y proteger a los civiles de los crímenes y abusos cometidos en los disturbios de 2002. ${ }^{44}$

Voces antagónicas a la tan nombrada ola Modi afirman que dicho fenómeno fue fabricado por los medios de comunicación con millones de dólares de por medio derrochados en publicidad. Tanto se habló de la supuesta ola que término por devenir en una. ${ }^{45}$ Entre otras personas opositoras, el señor Kishore, encargado de la librería de Gujarat Sahitya Parishad en Ahmedabad, muestra desaliento ante la llegada de Modi; refiere que se trata de un gobierno autoritario y antiislámico, un gobierno que, a su parecer, sin duda conducirá a una mayor división social bajo líneas religio-

41 "Modi Is Being Demonised: Madhu Kishwar", The Hindu, 21 de marzo de 2014 [http:/ /www.thehindu.com/news/cities/bangalore/modi-is-being-demonised-madhu-kishwar/article5815901.ece].

42 "No Communalism in Modi's DNA: Madhu Kishwar", Business Standard, 3 de abril de 2014 [http://www.business-standard.com/article/elections-2014/no-com munalism-in-modi-s-dna-madhu-kishwar-114040300988_1.html].

${ }^{43}$ Prashant, una organización dirigida por el padre jesuita Cedric Prakash, asimismo, Human Rights Watch y Amnistía Internacional son algunas instancias que han dado seguimiento a las investigaciones sobre los disturbios. Véase por ejemplo, “We Have No Orders to Save You'. State Participation and Complicity in Comunal Violence in Gujarat", vol. 14, núm. 3(C), 2002, en la compilación de documentos e imágenes de la ong, Prashant en el CD "Gujarat Carnage".

${ }^{44}$ Reporte de Amnistía Internacional 2005, op. cit.

${ }^{45}$ Tusha Mittal, op. cit. 
sas. ${ }^{46}$ Entre sectores de musulmanes en Gujarat, la consternación también ha sido evidente: la pregunta que se plantean es qué deben esperar del gobierno de Modi cuando en todo momento estuvo lejos de preocuparse por las carencias existentes en los guetos de musulmanes. "Modi no está interesado en nosotros", es la apreciación de los habitantes de estas áreas que decidieron quedarse ahí porque a la fecha no se sienten seguros para volver a sus hogares luego de 2002. Sólo en zonas de musulmanes es que sienten algo de sosiego. ${ }^{47}$

Finalmente, el triunfo de Narendra Modi demuestra que el derroche de recursos fue una estrategia efectiva para allegarse al poder central junto con la repetición porfiada de un nivel de desarrollo que aunque considerable no goza de singularidad y está en paralelo con el de otros gobiernos regionales. El monumental esfuerzo y promoción invertido en el proyecto de Vibrant Gujarat logró desviar la atención del pasado ominoso de Modi cuya omisión en detener las agresiones revanchistas posibilitó la articulación de uno de los episodios más violentos de la India contemporánea.

La llegada al gobierno central del вJP con una situación inmejorable por su mayoría abrumadora en la Lok Sabha genera mucha expectación entre los diversos sectores de la población. Modi ha hecho demasiado por proyectar una imagen progresista, lo que sus seguidores esperan de él. Sin embargo, el lastre que el político arrastra todavía por los disturbios de 2002 también es influyente y siembra total desconfianza entre sus opositores.

Por lo pronto, aunque el exjefe de Gujarat ha hablado de una idea de inclusión, los ministros que ha nombrado provienen de entre los militantes del BJP en exclusivo. Asimismo, que haya invitado al mandatario de Pakistán a su toma de posesión como primer ministro podría arrojar testimonio de una actitud menos beligerante hacia el histórico "enemigo" de India. No obstante, sus declaraciones sobre la inmigración bangladeshí de musulmanes en India sigue revelando una actitud hostil hacia los musulmanes. Además, la ministra de asuntos de minorías designada por Modi,

${ }^{46}$ Conversación con el señor Kishore, Ahmedabad, marzo de 2014.

${ }^{47}$ Surabhi Vaya, op. cit. 
Najma Heptullah, no distensa la situación cuando ya ha referido que los musulmanes en India no son una minoría a pesar de que constituyen tan sólo $14 \%$ de la población. ${ }^{48}$ Esta consideración lesiona los derechos a los que los musulmanes pueden acceder al ser considerados en dicho estatus.

A pesar de la llegada de Modi a primer ministro con un proyecto de desarrollo y el compromiso de reducir las tensiones comunales, algunas minorías están en alerta por lo que consideran un ascenso del fundamentalismo hindú a escasos meses de la asunción de Modi como primer ministro. Entre enero-febrero de 2015, por lo menos cinco iglesias han sido saqueadas en Delhi. Ante dicha situación, la postura de Modi ha sido el silencio y ninguna condena para estos actos. De aquí que minorías cristianas dicen sentirse amenazadas y acusan que la llegada de Modi ha sido paralela al incremento de la tensión social. ${ }^{49}$

En este estado de cosas, si la consigna de amplios sectores de la sociedad para votar por Modi fue erradicar al Congreso a toda costa para penalizarlo por su corrupción y su mala gestión política, la democracia y el secularismo en India se verían beneficiados si la propia sociedad civil acotara el ejercicio de gobierno de Modi hacia una esfera de respeto por las diversas comunidades para tratar de romper el círculo vicioso de estrategias proselitistas comunales. Modi se mantuvo como jefe de gobierno de Gujarat en una plataforma de antagonismo hacia las minorías; acaso intente conducir su gobierno por estas líneas. Sin embargo, si luego de 2002 fue marginado como político por la comunidad internacional a manera de penalización, ésta es una estrategia que no resulta adecuada para implementarse. Hoy en día, Modi es un hombre al cual ya no se puede ignorar; al contrario, se debe inquirir sobre quién es realmente, qué intenta y cómo lo llevará a cabo. ${ }^{50}$ De este modo, lo

48 Irfan Ahmad, "Are India's Muslims a Minority?”, Aljazeera English, 5 de junio de 2014, [http://www.aljazeera.com/indepth/opinion/2014/06/are-india-musli ms-minority-201463122145787274.html]

49 "Rise of Hindu Nationalism Alarms Indian minorities", Aljazeera English, 6 de febrero de 2015 [http://www.aljazeera.com/programmes/insidestory/2015 /02/ rise-hindu-nationalism-alarms-indian-minorities-modi-150206182511244.html] .

${ }^{50}$ Opinión del embajador de Estados Unidos en India, Sankarshan Thakur, 
congruente es un seguimiento meticuloso a su administración para evitar la conducción de un gobierno hostil a las minorías, rasgo distintivo de su larga administración en Gujarat.

\section{BibLIOGRAFÍA}

Ahmad, Irfan, "Are India's Muslims a Minority?", Aljazeera English, 5 de junio de 2014 [http://www.aljazeera.com/indepth/opinion/2014/ 06/are-india-muslims-minority-201463122145787274.html].

Bobbio, Tommaso, "From Ahmedabad to Karnavati", en Sharmina Mawani y Anjoom A. Mukadam (eds.), Globalisation, Diaspora and Belonging. Exploring Transnationalism and Gujarati Identity, Delhi, Rawat, 2014, pp. 255-276.

Burke, Jason, "Narendra Modi's Landslide Victory Shatters Congress Grip to India", The Guardian, 16 de mayo de 2014 [http:/ /www.theguardian. com/world/2014/may/16/narendra-modi-victory-congress-indiaelection].

Darlymple, William, "Narendra Modi: Man of the Masses", New Statesman, 12 de mayo de 2014 [http://www.newstatesman.com/politics/2014/ 05/narendra-modi-man-masses].

Ghosh, Partha, BJP and the Evolution of Hindu Nationalism: From Periphery to Centre, Nueva Delhi, Manohar Publishers, 1999.

Gowda, Rajeev, "Is the Development in Narendra Modi's Gujarat All Virtual?”, DNA, 21 de abril de 2014 [http:/ /www.dnaindia.com/analysis/ standpoint-is-the-development-in-narendra-modi-s-gujarat-all-virtual-1980563].

Gupta, Dipankar, "Gujarat: What Miracle?”, The South Asian Idea Web Blog [https://thesouthasianidea.wordpress.com/2009/03/18/gujaratwhat-miracle/].

— Justice before Reconciliation. Negotiating a 'New Normal' in Post-Riot Mumbai and Ahmedabad, Nueva Delhi, Routledge, 2011.

\footnotetext{
"Pracharak to Pradhanmantri: Narendra Modi’s Extraordinary Journey", 26 de mayo de 2014 [http://sankarshanthakur.com/2014/05/26/pracharak-to-pradhanmantri-narendra-modis-extraordinary-journey/] .
} 
Hashmi, Sameer, "Narendra Modi: India’s Economic Saviour?”, BBC, 17 de mayo de 2014 [http://www.bbc.com/news/business-27412507].

Hensman, Rohini, "The Gujarat Model of Development: What Would It Do to the Indian Economy?", Economic and Political Weekly, vol. 49, núm. 11, marzo de 2014 [http://www.epw.in/web-exclusives/gujarat-model-development.html].

Jaffrelot, Christophe (ed.), Hindu Nationalism: A Reader, Princeton, Princeton University Press, 2007.

y Thomas Blom Hansen (eds.), The BJP and the Compulsions of Politics in India, Delhi-Nueva York, Oxford University Press, 1998.

Kuruvachira, J., Politcisation of Hindu Religion in Postmodern India. An Anatomy of the Worldviews, Identities and Strategies of Hindu Nationalists in Bharatiya Janata Party, Delhi, Rawat Publications, 2008.

Langa, Mahesh y Divyaraj Gadhavi, “Ahmedabad's segregated Muslims”, Aljazeera English, 30 de abril de 2014 [http://www.aljazeera.com/inde pth/inpictures/2014/04/pictures-ahmedabad-segregated-m-20 1442316259141306.html].

Malik, Yogendra K. y V. B. Singh, Hindu Nationalists in India: The Rise of the Bharatiya Janata Party, Nueva Delhi, Vistaar Publications, 1994.

Mehta, Nalin, "Ashis Nandy vs. The State of Gujarat: Authoritarian Developmentalism, Democracy and the Politics of Narendra Modi”, en Nalin Mehta y Mona G. Mehta (eds.), Gujarat beyond Gandhi: Identity, Conflict and Society, Delhi, Routledge, 2010, pp. 156-183.

Mittal, Tusha, "From Marx to Modi in West Bengal?", Aljazeera English, 27 de mayo 2014 [http://www.aljazeera.com/indepth/features/2014/ 05/from-marx-modi-west-bengal-201452711380973919.html].

"Modi: From Tea Boy to India’s Leader", Aljazeera English, 27 de mayo de 2014 [http://www.aljazeera.com/news/asia/2014/05/modi-from-teaboy-india-pm-20145139742599119.html].

"Modi Is Being Demonised: Madhu Kishwar", The Hindu, 21 de marzo de 2014 [http://www.thehindu.com/news/cities/bangalore/modi-is-be ing-demonised-madhu-kishwar/article5815901.ece].

Narayan, Badri, Fascinating Hindutva. Saffron Politics and Dalit Mobilisation, Nueva Delhi, Sage, 2009.

"No communalism in Modi's DNA: Madhu Kishwar", Business Standard, 3 de abril de 2014 [http://www.business-standard.com/article/elec- 
tions-2014/no-communalism-in-modi-s-dna-madhu-kishwar-1140 40300988_1.html].

Prabhakar, Binoy, "How an American Lobbying Company APCO Worldwide Markets Narendra Modi to the World", The Economic Times, 9 de diciembre de 2012 [http:/ / articles.economictimes.indiatimes.com/201 2-12-09/news/35689601_1_apco-worldwide-vibrant-gujarat-niira-radia]. Puniyani, Ram, "Modi Coming to Power: An Appraisal”, Academia.edu [http: //www.academia.edu/8781597/Modi_coming_to_Power_An_ Appraisal].

Puri, Geeta, Bharatiya Jana Sangh: Organisation and Ideology, Delhi: A Case Study, Nueva Delhi, Sterling Publishers Pvt. Ltd., 1980.

Reporte de Amnistía Internacional 2005 [http://www.amnesty.org/en/ library/asset/ASA20/001/2005/en/110d0c4c-d53a-11dd-8a23d58a49c0d652/asa200012005en.pdf].

"Rise of Hindu Nationalism Alarms Indian Minorities", Aljazeera English, 6 de febrero de 2015 [http://www.aljazeera.com/programmes/insidestory/2015/02/rise-hindu-nationalism-alarms-indian-minoritiesmodi-150206182511244.html].

Sanghavi, Nagindas, Gujarat at Cross-Roads, Mumbai, Bharatiya Vidya Bhavan, 2010.

Sankarshan Thakur, "Pracharak to Pradhanmantri: Narendra Modi's Extraordinary Journey", 26 de mayo de 2014 [http:/ / sankarshanthakur. com/2014/05/26/pracharak-to-pradhanmantri-narendra-modis-extraordinary-journey/].

Subramanium, K. S., "Truth Behind the Fire in Sabarmati Express", Mainstream Weekly, vol. 49, núm. 16, 9 de abril de 2011 [http://www.mainstreamweekly.net/article2684.html].

The Myth of Gujarat's Exceptional GDP Growth Under Modi”, 7 de octubre 2013 [http://www.centreleftindia.wordpress.com/2013/10/07/ the-myth-of-gujarats-exceptional-gdp-growth-under-modi/].

Vaya, Surabhi, “Gujarat: 'We Don't want Modi or BJP'”, First Politics, 1 de mayo de 2014 [http://www.firstpost.com/politics/gujarat-we-dontwant-modi-or-bjp-say-muslims-in-juhapura-1503671.html

CD compilación de documentos e imágenes, "Gujarat Carnage”, Prashant. Conversación con el señor Kishore, Ahmedabad, marzo de 2014. 